\title{
Pengaruh media pop up book berbasis literasi digital untuk meningkatkan keterampilan berbicara siswa kelas rendah
}

\author{
Muhamad Yusron ${ }^{1}$, Ari Metalin Ika Puspita ${ }^{2}$, Flora Puspitaningsih ${ }^{3}$ \\ STKIP PGRI Trenggalek, Trenggalek, Indonesia
}

\begin{abstract}
ABSTRAK
Tujuan penelitian dan pengembangan ini untuk meningkatkan keterampilan berbicara siswa melalui media pор ир book berbasis literasi digital serta melihat perbedaan sebelum dan sesudah penggunaan media рор up book berbasis literasi digital. Metode penelitian yang digunakan dalam penelitian ini adalah jenis penelitian kuantitatif dengan desain penelitian Pretest-posttest. Teknik analisis data dalam penelitian ini yaitu independent sample t-test. Hasil penelitian ini adalah media pop up book berbasis literasi digital terdapat perbedaan hasil keterampilan berbicara sebelum dan sesudah penggunaan media pop up book berbasis literasi digital dan terdapat peningkatan keterampilan berbicara siswa setelah penggunaan media $p \circ p$ up book berbasis literasi digital.
\end{abstract}

Kata-kata Kunci: Keterampilan Berbicara, Literasi Digital, Media Pop Up Book

\section{Development of digital literacy based pop-up media to improve speaking skills of low grade students}

\begin{abstract}
The purpose of this research and development is to improve students' speaking skills through digital literacy-based pop-up media and to see differences before and after the use of digital literacy-based pop-up media. The research method used in this study is a type of quantitative research with a pretest-posttest research design. The data analysis technique in this study is the independent sample t-test. The results of this study are digital literacy based pop up books, there are differences in the results of speaking skills before and after the use of digital literacy based pop up books and there is an increase in students' speaking skills after using digital literacy based pop up books.
\end{abstract}

Keywords: digital literacy; Pop Up Book Media; Speaking Skill

\section{PENDAHULUAN}

Pendidikan merupakan salah satu kebutuhan primer yang harus dipenuhi di dalam kehidupan. Menurut Undang-Undang No 20 Tahun 2003 menyatakan bahwa pendidikan adalah usaha sadar dan terencana untuk mewujudkan suasana belajar dan proses pembelajaran agar peserta didik secara aktif mengembangkan potensi dirinya untuk memiliki kekuatan spiritual keagamaaan, pengendalian diri, kepribadian, kecerdasan, akhlak mulia, serta ketrampilan yang diperlukan dirinya, masyarakat, bangsa, dan Negara. Pendidikan yang bermutu ditentukan oleh kerjasama yang erat antara pemerintah dan para stake bolder pendidikan. Dewasa ini, seiring dengan perkembangan zaman permasalahan di dalam dunia pendidikan selalu memunculkan persoalan-persoalan baru yang tidak pernah terpikirkan sebelumnya. Menurut Puspita (2016) permasalahan pada pendidikan di dunia baik itu permasalahan eksternal maupun 
internal perlu dicarikan solusi terhadap permasalahan yang terjadi pada dunia pendidikan. Salah satu permasalahan pendidikan yaitu sistem pendidikan yang lemah. Sehingga permasalahan-permasalahan dalam pendidikan tersebut harus segera diatasi agar pendidikan mampu berkembang dengan baik. Salah satu yang menyebabkan pendidikan di Indonesia tidak dapat berkembang adalah keterampilan berbicara siswa. Menurut Tarigan (dalam Cahyani dkk, 2017) menyatakan bahwa berbicara merupakan kemampuan dalam melafalkan kata-kata, menyampaikan pikiran, perasaan, gagasan serta mengeksperikan sesuatu yang diungkapkan. Sedangkan menurut Haryadi dan Zamzam (dalam Astuti, 2015) menyatakan bahwa bentukbetuk kegiatan untuk melatih keterampilan berbicara dalam Bahasa Indonesia antara lain: bercerita, berdialog, berpidato/berceramah, dan berdiskusi. Kemampuan berbicara mempunyai banyak jenis salah satunya yaitu berbicara bebas untuk menyampaikan hasil bercerita.

Kemampuan berbicara untuk menyampaikan hasil bercerita siswa masih sangat rendah. Berdasarkan hasil observasi dan wawancara yang dilakukan di SDN 2 Surodakan pada kelas III tanggal 3 Desember 2019 diperoleh data bahwa hampir 82\% peserta didik belum mampu menyampaikan maksud yang diinginkan dalam bentuk cerita, seperti contohnya saat peserta didik membaca kemudian guru meminta peserta didik untuk mengemukakan cerita yang telah dibaca tersebut dengan bercerita di depan peserta didik lainnya, namun peserta didik tidak mampu bercerita bahkan sulit untuk mengungkapkan hal yang siswa ketahui dari proses membaca tersebut.

Literasi merupakan kemampuan individu dalam menulis, membaca, dan berbicara. Menurut Kemendikbud (2017) menyatakan bahwa literasi merupakan upaya menyeluruh yang dilaksanakan melalui pembangunan ekosistem pendidikan, baik di lingkungan keluarga, sekolah maupun masyarakat. Sedangkan menurut Adam dan Hamm (dalam Widyastuti dkk 2016) mengatakan bahwaliterasi merupakan kecakapan dalam melihat, mendengar, menulis, membaca, berpikir dan berbicara. Saat ini literasi yang sedang dikembangkan yaitu literasi digital. Menurut Kemendikbud (2017) literasi digital adalah pengetahuan dan kecakapan untuk menggunakan media digital, alat-alat komunikasi, atau jaringan dalam menemukan, mengevaluasi, menggunakan, membuat informasi, dan memanfaatkannya secara sehat, bijak, cerdas, cermat, tepat, dan patuh hukum dalam rangka membina komunikasi dan interaksi dalam kehidupan sehari-hari. Mengingat kondisi saat ini teknologi semakin maju dan peserta didik lebih menyukai hal-hal yang berbau media digital. Selain itu literasi digital memerlukan kemampuan dalam memahami penggunaan perangkat teknologi guna untuk memperoleh informasi yang tersampaikan melalui perangkat teknologi. Selain itu, dalam literasi digital terpacu pada pengetahuan, keterampilan, dan pemahaman dalam menggunakan media pembelajaran.

Media pembelajaran merupakan salah satu alat yang dapat menarik perhatian peserta didik sehingga mereka lebih mudah memahami materi yang disampaikan guru. Gagne dan Briggs (dalam Pramesti, 2015) mengatakan bahwa media pembelajaran merupakan komponen dari sumber belajar yang 
digunakan sebagai alat untuk menyampaikan isi materi pelajaran. Contoh bentuk media tiga dimensi adalah Pop-Up Book. Pop-up adalah seni kertas ketika yang dibuka muncul lipatan kertas yang membuat kita terkejut dan menyenangkan Taylor dan Bluemel (dalam Setyawan dkk, 2014). Sedangkan menurut Menurut Dzuanda (dalam Solichah 2018), menyatakan bahwa buku pop up memiliki kelebihan diantaranya yaitu ketika halaman buku dibuka bagian tertentu nantinya bias bergeser, mampu memberikan kejutan yang dapat menimbulkan rasa ingin tahu terhadap materi yang disampaikan memiliki makna yang kuat terhadap isi dari pop up book. Pengembangan pop up perlu dilakukan sehingga isi dari media pop up book dapat menarik perhatian siswa.

\section{METODE PENELITIAN}

Jenis penelitian yang digunakan dalam penelitian ini yaitu Penelitian Kuantitatif. Desain yang digunakan dalam penelitian ini menggunakan Pretest dan Postest. Struktur Desain penelitian ini adalah sesuai gambar 1 di bawah ini.

\section{\begin{tabular}{lll}
$\mathbf{O}_{1}$ & $\mathrm{X}$ & $\mathbf{O}_{2}$ \\
\hline
\end{tabular}}

Gambar 1 Desain Penelitian PretestPostest

Ket:

$\mathrm{O}_{1}=$ Nilai Pretest (sebelum penggunaan media),

$\mathrm{O}_{2}=$ nilai Postest (sesudah penggunaan media)

$\mathrm{X}=$ perlakuan dengan media.

Lokasi penelitian ini yaitu di SDN 2 Surodakan Kabupaten Trenggalek. Sedangkan Subyek penelitian ini yaitu siswa Kelas III-C. Teknik sampling yang digunakan peneliti dalam menentukan sampling adalah teknik purposive sampling.

Instrumen yang digunakan dalam penelitian ini yaitu Lembar Angket dan pedoman wawancara. Data yang dikumpulkan dalam penelitian ini berupa data kuantitatif. Data kuantitatif didapatkan dari keterampilan berbicara. Untuk menguji keefektifan penerapan pada media $p \circ p$ up book berbasis literasi digital dengan formula independent sample t-test dengan bantuan software SPSS 25.0.

\section{HASIL DAN PEMBAHASAN}

Pada uji coba medi pop up book berbasis literasi digital akan melihat pengaruh media pop up book terhadap kemampuan keterampilan berbicara siswa dengan menggunakan angket pengukuran 
kemampuan keterampilan berbicara. Pada uji coba media pop up book, selain melihat nilai angket respon siswa dalam menggunakan media $p \circ p$ up book berbasis literasi digital, juga melihat hasil kemampuan keterampilan berbicara melalui angket pengukuran kemampuan keterampilan berbicara dengan penilaian peneliti. Hasil pengukuran keterampilan berbicara siswa pada uji coba media pop up book disajiakan ke dalam deskripsi data. Hasil deskripsi keterampilan berbicara siswa disajiakan dalam Tabel 1 berikut.

Tabel 1 Deskripsi Keterampilan Berbicara Siswa

\begin{tabular}{lccccc}
\hline \multicolumn{1}{c}{ Variabel } & $\mathrm{N}$ & Minimum & Maximum & Mean & Std. Devisiation \\
\hline $\begin{array}{l}\text { Keterampilan } \\
\text { berbicara }\end{array}$ & 15 & 15 & 60 & 37,5 & 7,5 \\
\hline
\end{tabular}

Berdasarkan Gambar 1 hasil data yang diperoleh dilakukan pengkategorian keterampilan berbicara siswa menjadi tiga kategori yaitu tinggi, sedang dan rendah. Hasil deskripsi keterampilan berbicara siswa disajiakan dalam Gambar 2 berikut.

Tabel 2 Kategori Keterampilan Berbicara Siswa

\begin{tabular}{ccccc}
\hline Kategori & Formula & Rentan skor & Frekuensi & Persentase \\
\hline \multirow{2}{*}{ Tinggi } & $\mathrm{M}+1 \mathrm{SD} \leq \mathrm{X}$ & \multirow{2}{*}{$45 \leq \mathrm{X}$} & 13 & 100 \\
\hline \multirow{2}{*}{ Sedang } & $\mathrm{M}-1 \mathrm{SD} \leq \mathrm{X}<\mathrm{M}+1 \mathrm{SD}$ & \multirow{2}{*}{$30 \leq \mathrm{X}<45$} & 0 & 0 \\
& $37,5-7,5 \leq \mathrm{X}<37,5+7,5$ & & \\
\hline \multirow{2}{*}{ Rendah } & $\begin{array}{c}\mathrm{X}<\mathrm{M}-1 \mathrm{SD} \\
\mathrm{X}<37,5-7,5\end{array}$ & $\mathrm{X}<30$ & 0 & 0 \\
& Total & & 13 & 100 \\
\hline
\end{tabular}

Berdasarkan Gambar 2 hasil data yang diperoleh diketahui bahwa kategori keterampilan berbicara siswa kelas kontrol mendapatkan kategori tinggi 13 siswa (100\%), kategori sedang 0 siswa (0\%) dan kategori rendah 0 siswa $(0 \%)$.

Uji prasyarat analisis data dibutuhkan untuk mengetahui bahwa anlisis data yang digunakan untuk pengujian hiptesis dapat dilanjutkan atau tidak. Analisis ini mensyaratkan bahwa data berasal dari populasi yang berdistribusi normal dan kelompok-kelompok yang dibandingkan homogen. Hasil pengujian prasyarat sebagai berikut.

Uji normalitas dilakukan untuk mengetahui apakah data yang diperoleh berdistribusi normal atau tidak. Uji ormalitas dilakukan dengan menggunakan Kolmogorof Smirnov dengan menggunakkan bantuan program SPSS 25.0 dengan taraf signifikansi 0,05. Apabila nilai signifikansi hasil nilai pengukuran keterampilan berbicara siswa $>0,05$ maka hasil nilai pengukuran keterampilan berbicara siswa terdistribusi normal. Hasil pengujian normalitas dapat dilihat pada Tabel 3 berikut ini.

Tabel 3 Hasil Uji Normalitas

Tests of Normality 


\begin{tabular}{lccc}
\hline \multirow{2}{*}{ Kontrol } & \multicolumn{3}{c}{ Shapiro-Wilk } \\
\cline { 2 - 3 } & Statistic & df & Sig. \\
\cline { 2 - 3 } Eksperimen & 942 & 28 &, 125 \\
\hline
\end{tabular}

Berdasarkan hasil uji normalitas pada Tabel 3 dengan menggunakan Kolmogorof Smirnov data pengukuran keterampilan berbicara siswa dari hasil kelas control dan kelas eksperimen memiliki nilai signifikansi $>0,05$ hasil tersebut menunjukkan bahwa keterampilan berbicara berdistribusi normal. Hal ini dibuktikan dengan nilai signifikansi untuk nilai kelas kontrol diperoeh hasil 0,051 >0,05 dengan nilai kelas eksperimen diperoleh hasil 0,200 >0,05.

Uji homogenitas digunakan untuk mengetahui suatu varina atau keberadaan data dari dua atau lebih kelompok bersifat homogen (sama) atau heterogen (tidak sama). Uji homogenitas dilakukan dengan menggunakan One-way ANOVA yang dihitung menggunakan bantuan program SPSS dengan taraf signifikansi 0,05. Apabila nilai signifikansi $>0,05$ maka distribusi data adalah homogenitas. Hasil uji homogenitas dapat dilihat data pada Tabel 4 sebagai berikut.

Tabel 4 Hasil Uji Homogenitas

\begin{tabular}{cccc}
\hline $\begin{array}{c}\text { Levene } \\
\text { Statistic }\end{array}$ & df1 & df2 & Sig. \\
\hline, 185 & 1 & 54 &, 669
\end{tabular}

Berdasarkan data Tabel 4 hasil data pengukuran keterampilan berbicara siswa dari hasil kelas kontrol dan kelas eksperimen memiliki nilai signifikansi $>0,05$ yang berarti data keterampilan berbicara berdistribusi normal. Hal ini dibuktikan dengan nilai signifikansi sebesar 0,669 (> 0,05), yang berarti varian dari kemampuan keterampilan berbicara terdistribusi homogeny.

Uji hipotesis yang digunakan dalam penelitian ini adalah independent sample t-tes digunakan untuk mengetahui apakah terdapat perbedaan rata-rata dua sampel yang tidak berpasangan. Uji independent sample t-tes menggunakan bantuan SPSS 25.0. hasil uji hipotesis dapat dilihat melalui Tabel 5 sebagai berikut.

Tabel 5 Hasil Uji Hipotesis

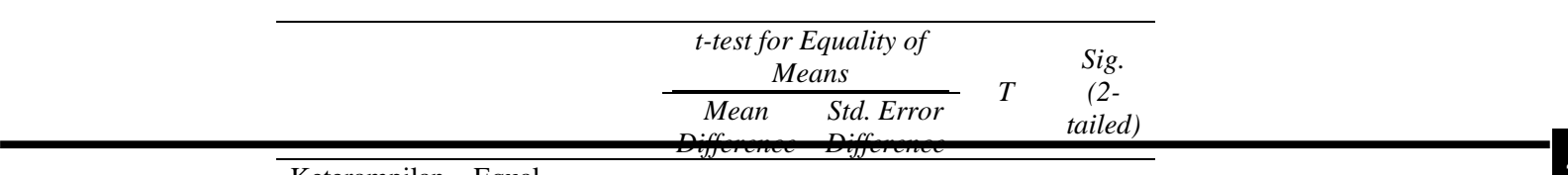


Berdasarkan hasil Tabel 5 diperoleh nilai sig. (2-tailed) kelas kontrol 0,00 dan kelas eksperimen 0,00. Maka dapat disimpulkan bahwa Ho ditolak yang berarti ada perbedan setelah penggunaan media pop up book berbasis literasi digital terhadap kemampuan berbicara.

Media $р о р$ ир merupakan salah satu media gambar. Oleh sebab itu, $p \circ p$ up termasuk dalam kategori media berbasis visual. Sebagai media pembelajaran, $p$ р $и$ р memiliki keunggulan yaitu untuk menjelaskan gambar yang kompleks, Pop up book berbasis literasi digital menyediakan umpan pembelajaran, karena bagi siswa, ilustrasi visual pada isi $p \circ p$ up dapat menggambarkan konsep yang abstrak menjadi jelas serta memberikan kesan yang menarik, dan materi yang dikemas pada media pop up book menjadi lebih mudah untuk diingat dan dipahami. Selain itu dengan dilengkapi alat audio yang dapat memungkinkan peserta didik dapat mendengar isi materi dan berinteraksi langsung dengan media tersebut, kenyamanan dalam belajar dan konsentrasi siswa dapat dipengaruhi penggunaan musik backsound pada media pop up book berbasis literasi digital. Media pop up book yang dikembangkan memiliki Bluetooth yang dapat dihubungkan melalui perangkat smartphone untuk menyampaikan materi berupa audio. Berdasarkan uji coba media $p \circ p$ up book berbasis literasi digital memiliki kategori valid, layak, dan menarik. Media pop up book berbasis literasi digital efektif mampu meningkatkan kemampuan keterampilan berbcara siswa serta terdapat perbedaan yang signifikan sebelum dan sesudah terhadap penggunaan media $p \circ p$ up book berbasis literasi digital.

Hasil ini sesuai dengan penelitian terdahulu yang dilakukan oleh Riani (2015) yang berjudul "Peningkatan Keterampilan Berbicara Menggunakan Media Pop Up Siswa Kelas III SDN Gembongan Kecamatan Sentolo Kabupaten Kulon Progo" penelitian menunjukkan bahwa keterampilan berbicara dalam bentuk kegiatan bercerita siswa mengalami peningkatan melalui penggunaan media pop up. Sedangkan peneliti yang lain dilakukan oleh Rini (2018) yang berjudul "Pengembangan Media Pop Up Book Berbasis Kontekstual Pada Pembelajaran IPS Kelas III Sekolah Dasar” penelitian menunjukkan bahwa hasil validasi oleh validator media diperoleh rata-rata dengan tingkat kevalidan dengan kategori sangat baik dan hasil wawancara menunjukkan bahwa media ini sangat valid dan praktis. Sehingga dapat disimpulkan bahwa media pop up book yang dikembangkan mampu mengatasi permasalahan terkait keterampilan berbicara. Media ini mampu meningkatkan keterapialn berbicara siswa serta dapat menarik perhatian siswa untuk meningkatkan proses pembelajaran. 


\section{SIMPULAN}

Media pop up book yang digunakan di dalam proses pembelajaran mempunyai pengaruh signifikan terhadap kemampuan keterampilan berbicara siswa. Sehingga setelah menggunakan media pop up book, kemampuan keterampilan berbicara siswa mempunyai perbedaan sebelum dan sesudah menggunakan media pop up book. Media pop up book ini sangat sesuai digunakan sebagai media pembelajaran penunjang di dalam proses pembelajaran dalam peningkatan kemampuan keterampilan berbicara siswa kelas rendah. Pengembangan media $p \circ p$ up book sangat dibutuhkan agar siswa mempunyai pengalaman, wawasan serta pengetahuan luas dan mampu merangsang pola pikir siswa untuk menjadi generasi milineal.

\section{DAFTAR PUSTAKA}

Astuti, R. (2015). Peningkatan Keterampilan Berbicara Menggunakan Media Pop Up Siswa Kelas III SD Negeri Gembongan Kecamatan Sentolo Kabupaten Kulon Progo Tabun Ajaran 2014/2015. Skripsi tidak diterbitkan. Yogyakarta. Fakultas Ilmu Pendidikan Universitas Negeri Yogyakarta.

Astuti, Riani (2015) Peningkatan Keterampilan Berbicara Menggunakan Media Pop Up Siswa Kelas Iii Sd Negeri Gembongan Kecamatan Sentolo Kabupaten Kulon Progo Tabun Ajaran 2014/2015. S1 thesis, PGSD

Cahyani, N. A., Djuanda, D. dan Sudin, A. (2017). Penerapan Metode Vaks (Visual, Auditory, Kinestetbic, Sugestopedia) Untuk. Meningkatkan Keterampilan Berbicara Pada Materi Memerankan Tokoh Drama. Jurnal Pena Ilmiah. Vol 2, No.1.

Pramesti, J. (2015). Pengembangan Media Pop-Up Book Tema Peristiwa Untuk Kelas III SD. Yogyakarta. Fakultas Ilmu Pendidikan Universitas Negeri Yogyakarta

Puspita, A. M. I. (2016). Peningkatan Hasil Belajar Siswa Berbantuan Buku Teks Berbasis Kontekstual Untuk Siswa Kelas II Sekolah Dasar. Jurnal Pendidikan.

Setyawan, D., Usada. dan Mahfud, H. (2014). Penerapan Media Pop Up Book Untuk Meningkatkan Keterampilan Berbicara. Surakarta. FKIP Universitas Sebelas Maret.

Solichah, L. A. (2018). Pengarub Media Pop Up Book Terhadap Hasil Belajar Siswa Pada Mata Pelajaran Matematika Materi Bangun Datar Kelas IV SDN Wonoplintahan II Kecamatan Prambon. FIP Universitas Negeri Surabaya. Volume 06 Nomor 09.

Widyastuti, R. A. dan Nusantoro, R. (2016). Literasi Digital Pada Perempuan Pelaku Usaha Produktif Di Daerah Istimewa Yogyakarta. Jurnal Aspikom, Vol. 3, No.1. 